\title{
Sequelae of the adult respiratory distress syndrome
}

The adult respiratory distress syndrome (ARDS) is characterised by hypoxaemia, bilateral pulmonary infiltrates due to increased permeability, pulmonary oedema and, in most but not all instances, reduced lung compliance. The yearly incidence of ARDS is approximately six per 100000 .

ARDS may occur in response to various direct or indirect insults to the lung. Gastric aspiration, bacterial or pneumonia, major trauma, transfusion, and sepsis are among the most common causes (table). ${ }^{1-3}$ A generally standardised approach to the acute, supportive care of these patients has evolved which uses mechanical ventilation and positive end expiratory pressure (PEEP) ${ }^{4}$ but, despite increased experience in caring for these critically ill patients, the mortality of patients with ARDS remains at about $50 \% .{ }^{56}$ Death is often due to non-pulmonary causes, multiple organ system failure, or sepsis. ${ }^{7}$

Patients who survive an episode of ARDS may be asymptomatic and have normal pulmonary function, or they may have marked dyspnoea and severe physiological abnormalities. This editorial will review (1) the functional and physiological abnormalities seen in survivors of ARDS, (2) the predictors of pulmonary dysfunction in this population, and (3) those aspects of acute patient care which might adversely affect outcome.

\section{Functional and physiological abnormalities SYMPTOMS}

Although many series report that the majority of survivors of ARDS are symptom free, ${ }^{8-17}$ in most instances symptoms were not aggressively sought and documented. The larger of these series also appear biased in that they included patients with mild illness. Douglas and Downs ${ }^{9}$ identified 54 patients with acute respiratory failure who required mechanical ventilation and PEEP of whom 43 $(80 \%)$ survived; all survivors were asymptomatic at the time of hospital discharge. Of 15 patients evaluated for 1-30 months after ARDS by Yahav and colleagues ${ }^{15}$ none had symptoms, although only 10 of the $15(66 \%)$ required mechanical ventilation, and only seven of these $(47 \%)$ needed PEEP to maintain oxygenation.

Data from more recent series using a more rigorous definition of ARDS and including a more severely affected patient population suggest that symptom free recovery is somewhat less likely $(66 \%$ and $50 \%$ in the studies by Peters et $a l^{18}$ and Halevy et al, ${ }^{19}$ respectively). Interpretation of the study by Halevy et al, as well as that by Lakshminarayan et al ${ }^{20}$ in which $40 \%$ of the group was asymptomatic, is complicated by the high incidence of smoking in the two study populations, although only $11 \%$ of the patients had symptoms that could be related to smoking before ARDS.

Causes of adult respiratory distress syndrome

\section{Sepsis}

Multiple trauma

Hypertransfusion

Multiple fractures

Pneumonia

Aspiration

Near drownin

Near drowning

Inhalation injury

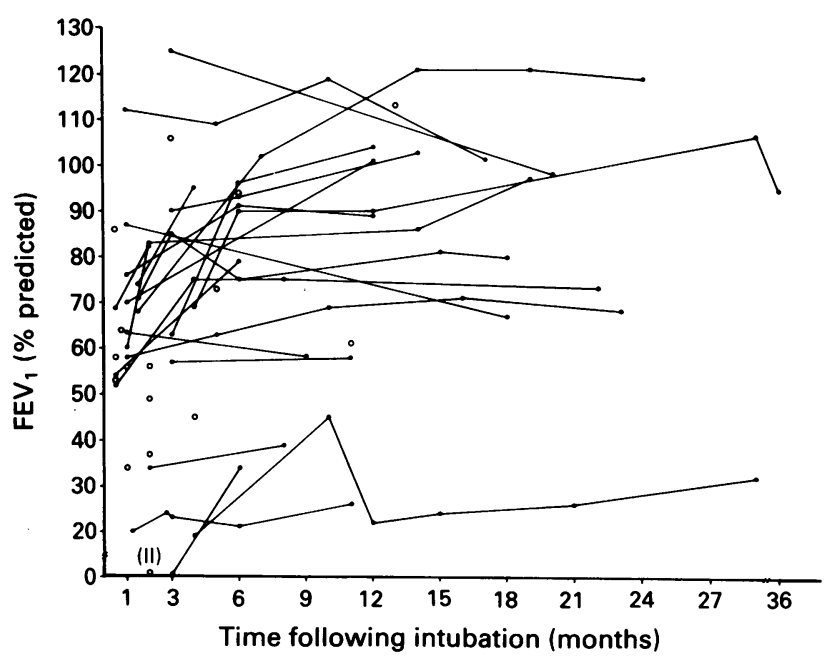

Figure 1 Variation of FEV, with time in survivors of ARDS. $\mathrm{O}=$ single values; $=$ multiple values. ${ }^{18}$

The most systematic evaluation of symptoms after ARDS was by Ghio and associates ${ }^{21}$ who found that 21 of 25 patients $(84 \%)$ studied between 0.3 and 7.5 years after their episode were symptomatic; $55 \%$ of those questioned at longer than one year remained so. The most common complaints were cough $(44 \%)$, sputum production $(50 \%)$, and dyspnoea (50\%). Although $29 \%$ of the entire population studied were smokers, smoking status had no association with symptoms. Interestingly, less than half of those with pulmonary complaints had abnormal pulmonary function test results. Conversely, those with abnormal pulmonary function were no more likely to be symptomatic than those with normal pulmonary function. Platypnoea and orthodeoxia that spontaneously resolved over several weeks have also been reported in one patient. ${ }^{11}$

Patients who recover from ARDS are at high risk for upper airway injury that may occur during their recovery. Laryngotracheal stenosis is a well recognised consequence of prolonged intubation, ${ }^{22}$ and vocal cord dysfunction is also common. The only symptomatic patient in the study of Elliott et al ${ }^{10}$ of 13 survivors of ARDS had dyspnoea because of bilateral vocal cord paralysis. Flow-volume loops should therefore be routinely ordered when evaluating patients with dyspnoea following an episode of ARDS. Since the sensitivity of the flow-volume loop for upper airway abnormalities is not known, an argument may also be made for patients to undergo laryngoscopy, bronchoscopy, or both.

Fortunately few of those who remain symptomatic have respiratory limitation sufficiently severe to impair their lifestyles. Of the 21 symptomatic patients in the study by Ghio et al only three (14\%) had moderate or severe physiological abnormalities, ${ }^{21}$ and only three of the 26 patients $(12 \%)$ reported by Peters et al $^{18}$ had dyspnoea which interfered with lifestyle. The symptoms of many patients improve during the first year after the episode of ARDS.

\section{SPIROMETRY}

Spirometric abnormalities are to be expected early in the post ARDS period (fig 1). In most patients parallel reduc- 
tions in forced expiratory volume in one second $\left(\mathrm{FEV}_{1}\right)$ and forced vital capacity (FVC) with a preserved FEV $_{1} /$ FVC value consistent with a restrictive defect are the predominant findings. These abnormalities may occasionally be severe. Forced expiratory volumes tend to improve over time so that normal or near normal values are generally seen by one year.

A subset of ARDS survivors (ranging from $14 \%$ to $50 \%)$ are left with at least mild airflow limitation $\left(\mathrm{FEV}_{1} /\right.$ FVC $<65 \%$, forced expiratory flow $25-75 \%$ of the vital capacity $<50 \%$ predicted) measured up to at least one year after the acute episode. ${ }^{9182021}$ Although in the study by Lakshminarayan and colleagues ${ }^{20}$ four of the five patients with airflow limitation were smokers, Elliott $e t a^{23}$ found a reduced $\mathrm{FEV}_{1} / \mathrm{FVC}$ value in four of 16 nonsmokers $(25 \%)$ one year after their episode of ARDS.

Increased airway resistance is characteristic of the acute phase of ARDS. ${ }^{24-27}$ During recovery, however, increased resistance is uncommon. ${ }^{17}$ Although this may, in part, be due to resolution of the airway inflammation, ${ }^{27}$ it probably results from the increase in total lung capacity (TLC) that occurs as ARDS resolves. ${ }^{26} \mathrm{~A}$ chronic increase in bronchial reactivity has been observed in response to methacholine or exercise in patients studied more than one year after ARDS ${ }^{2829}$ Unfortunately there are no good data that allow identification of those factors which predispose patients with ARDS to airflow limitation or airway reactivity.

\section{LUNG VOLUMES}

Lung volumes are reduced in many patients immediately after the episode of ARDS, but tend to improve during the first six months of recovery (fig 2). Elliott and colleagues ${ }^{23}$ found that seven of 16 patients $(46 \%)$ had a reduced TLC when tested less than two months after the onset of ARDS which returned to normal by three months in all instances. Similar observations were made by Peters $e t a l^{18}$ and by others. ${ }^{1415172330}$ An occasional patient may have severely reduced lung volumes which, without apparent explanation, do not improve. ${ }^{18}$

Some patients have residual volumes that remain chronically elevated with TLC being either normal or reduced, and with spirometric testing showing no evidence of airflow limitation. ${ }^{9141631}$ These patients may be manifesting the results of small airway injury during the acute phase of their ARDS. Churg and colleagues ${ }^{32}$ recently reported a series of patients who developed progressive radiological signs of air trapping before death. Extensive cyst formation was found at postmortem examination (fig 3). Histologically these cysts were lined by bronchiolar or metaplastic squamous epithelium. Marked bronchiolectasis has also been described. ${ }^{33}$ The airflow obstruction that occurs in some patients might have a similar pathophysiological explanation. These findings are

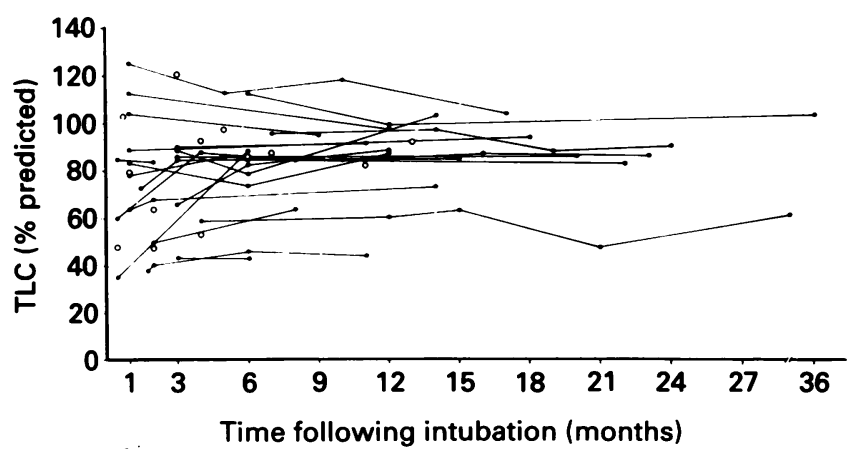

Figure 2 Variation of total lung capacity (TLC) with time in survivors of $A R D S . O=$ single values; $O=$ multiple values. ${ }^{18}$ in many ways similar to the severe bronchopulmonary dysplasia that occurs as a consequence of the infant respiratory distress syndrome. ${ }^{32}$ Bronchopulmonary dysplasia is usually seen in premature infants who require mechanical ventilation and high concentrations of oxygen for prolonged periods. In its most severe form it results in cyst formation, dilated terminal airways, air trapping, ${ }^{3435}$ and chronic airflow limitation in those who survive. ${ }^{34} 3637$

Because air trapping may be missed when lung volumes are measured by gas dilution techniques, plethysmographic determination is preferred when evaluating patients complaining of dyspnoea following ARDS.

\section{GAS EXCHANGE}

Reduced carbon monoxide transfer factor (TLCO) is the most common pulmonary function abnormality seen in patients recovering from ARDS. Soon after the acute episode $75-100 \%$ of patients will have abnormal values. ${ }^{1821}$ Although some of these patients improve during the first year, $40-80 \%$ of those studied had reductions that persisted even after one year. ${ }^{10141820212331}$ Fortunately, although chronic severe reductions of transfer factor may occur, the degree of abnormality observed is generally mild (fig 4).

Most patients have normal resting arterial blood gas tensions after recovering from ARDS. Exercise, however, may reveal more subtle gas exchange abnormalities. Elliott and colleagues ${ }^{10}$ found that 11 of 13 patients $(85 \%)$ had an alveolar-to-arterial oxygen difference $\left(\mathrm{A}-\mathrm{aDO}_{2}\right)$ that was normal at rest (measured one month after ARDS) but increased in all seven of those who were exercised. In

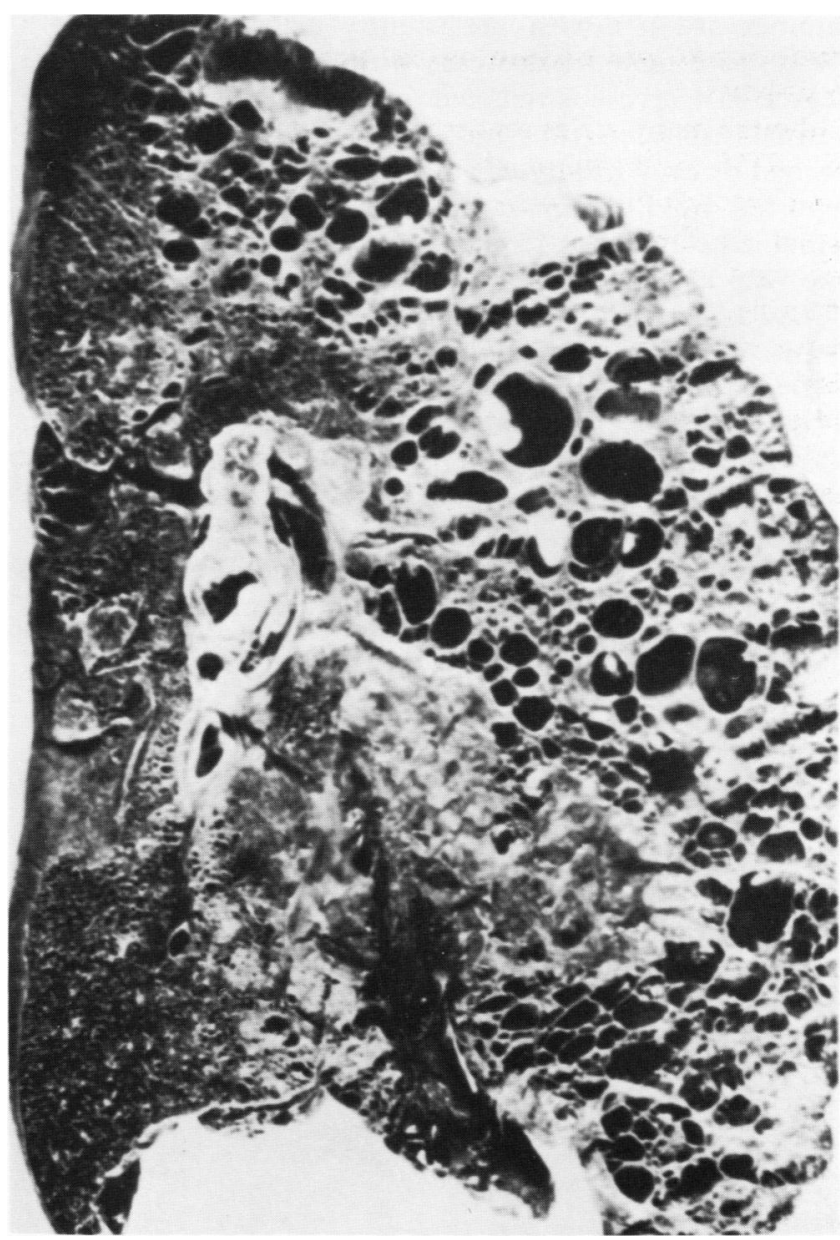

Figure 3 Lung of patient dying from ARDS showing diffuse cystic changes similar to that seen in infants with bronchopulmonary dysplasia. ${ }^{32}$ 


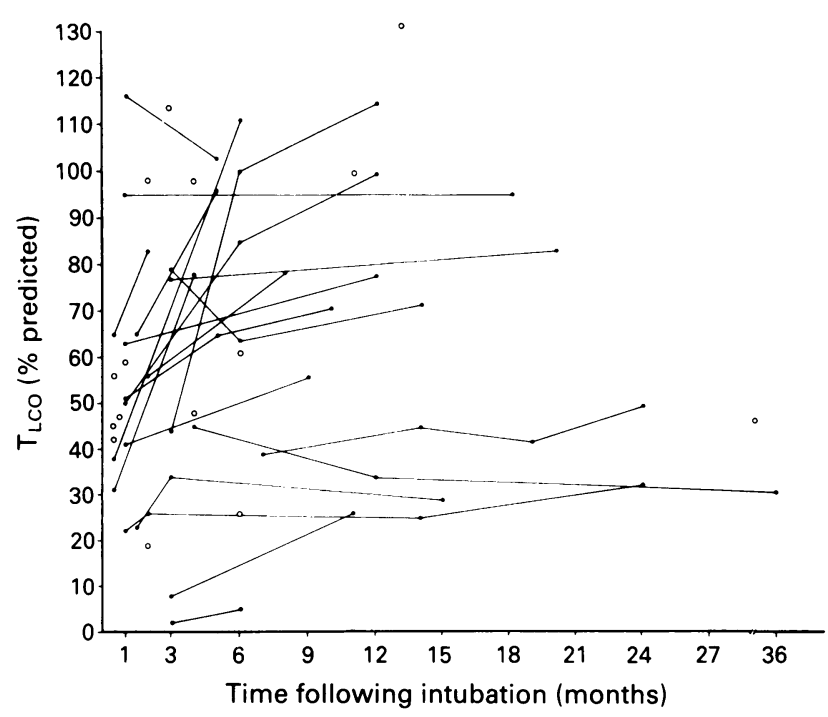

Figure 4 Variation of carbon monoxide transfer factor ( TLCO) with time in survivors of $A R D S . \bigcirc=$ single values; $O=$ multiple values. ${ }^{18}$

seven of nine subjects ( $78 \%$ ) followed for six to 19 months Buchser $e t a l^{30}$ found the $\mathrm{A}-\mathrm{aDo}_{2}$ increased with exercise despite normal spirometric values and lung volumes. Alberts $e t a l,{ }^{17}$ in their earlier review of this subject, noted that $48 \%$ of patients worsened their oxygenation with exercise.

The proportion of wasted ventilation $(\mathrm{VD} / \mathrm{VT})$ is often increased early in recovery from ARDS. ${ }^{1031}$ In many patients the VD/VT improves with time, ${ }^{10}$ but a substantial number are left with persistently elevated values. ${ }^{143031}$ Dead space tends to decrease with exercise, although the degree of decrease is reduced over that generally found in normal subjects. After recovery, shunt fraction may be normal or only mildly elevated, ${ }^{91431}$ although one patient reported by Buchser et $a l^{30}$ had a shunt fraction that remained elevated at $15 \%$ of the cardiac output more than one year after ARDS.

The failure of TLCO to return to normal in most survivors of ARDS contrasts with the improvement in spirometric values and lung volumes in these patients. Low TLCO values together with persistent abnormalities in $\mathrm{VD} /$ VT suggest that destruction or obstruction of the pulmonary vasculature may have occurred. There are abundant histological data to indicate that vascular loss does occur in the acute phase of ARDS. Bachofen and Weibel ${ }^{38}$ found striking reductions in the numbers of pulmonary capillaries seen in specimens obtained after the first 24 hours of
ARDS. Extensive thrombosis of pulmonary arteries has also been shown by both antemortem and postmortem arteriography (fig 5). ${ }^{39-41}$ Snow et al ${ }^{41}$ estimated morphometrically that the density of precapillary arterioles was reduced by $50 \%$. Extensive occlusion of the microvasculature by fibrin thrombi and non-thrombotic vascular obstruction caused by intimal proliferation and endothelial cell swelling is also seen in acute ARDS. ${ }^{40-42}$ Early vascular occlusion may correlate with the severity of ARDS and with survival from the acute event. ${ }^{39}$ In a study of six patients recovering from ARDS who underwent exercise testing, Buchser calculated a reduced pulmonary capillary blood volume. ${ }^{30}$ At this time a complete understanding of the causes of gas exchange abnormalities after ARDS is lacking. There are inadequate data available to conclude that finding these abnormalities in the immediate period after ARDS is predictive of long term pulmonary dysfunction.

\section{Predictors of pulmonary dysfunction}

It is difficult to attach prognostic importance to demographic or other patient characteristics that are unrelated to the episode of ARDS. In most studies patient numbers are too small to draw conclusions regarding whether the event associated with ARDS is correlated with outcome. Ghio and colleagues ${ }^{21}$ found no relationship between the precipitating cause and long term abnormalities of pulmonary function. Case reports have suggested that patients with ARDS caused by viral pneumonia may be predisposed to developing fibrosis and suffering long term functional abnormality. ${ }^{4344}$

Although several studies have suggested that older age predisposes to persistent abnormality of pulmonary function, ${ }^{9030}$ Ghio and associates ${ }^{21}$ also recently noted that patients younger than 20 had an increased risk of residual dysfunction.

The acute cellular response in ARDS is a neutrophilic alveolitis. ${ }^{45}$ Because cigarette smoking also increases the bronchoalveolar lavage neutrophil content, ${ }^{46}$ particularly in the setting of chronic bronchitis, ${ }^{47}$ smoking might be expected both to contribute to more severe acute disease and to worsen pulmonary function in survivors. Unfortunately this supposition is not supported by the available data. Elliott et $a l^{48}$ and Peters $e t$ al ${ }^{18}$ found no significant differences in follow up measurements of TLC, FVC, $\mathrm{FEV}_{1}$ or TLCo between smokers and non-smokers, although the maximum improvement in pulmonary function did seem to take longer in smokers. ${ }^{18}$

Nosocomial bacterial pneumonia is common in ARDS and is associated with worse acute pulmonary function and

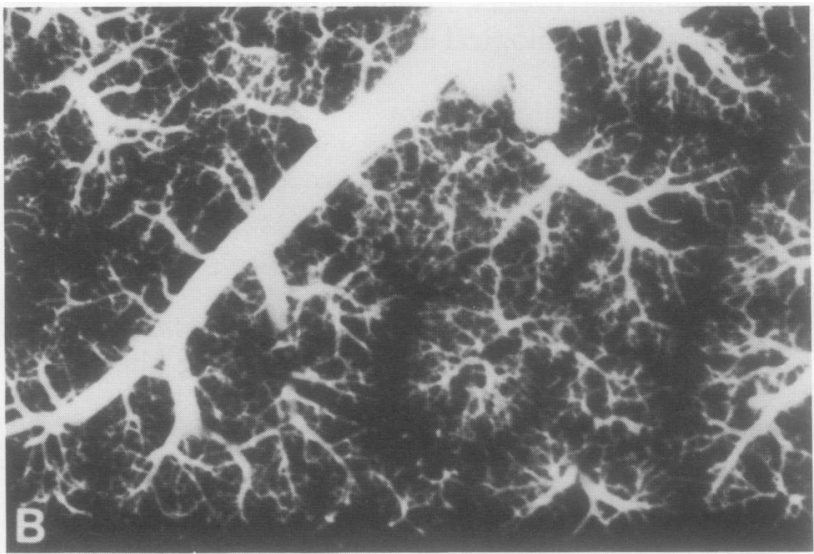

8

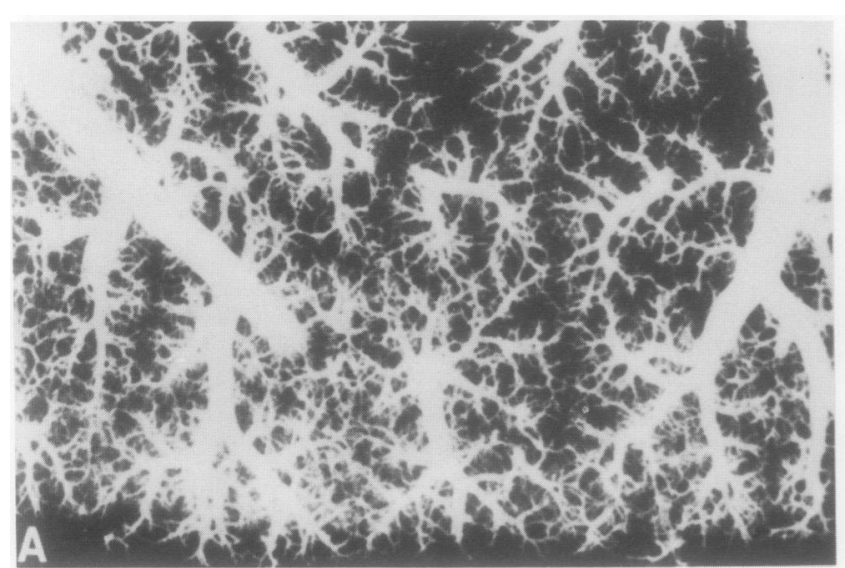

Figure 5 (A) Postmortem arteriogram of normal adult lung; the pleural surface is at the bottom. (B) Arteriogram of a patient with early $A R D S$ showing reduced filling of small arteries. ${ }^{40}$ Magnification $\times 2.4$, increased to $158 \%$ in origination. 
with increased mortality. ${ }^{49-52}$ In survivors of ARDS there is little to suggest that infectious complications worsen pulmonary function after recovery. Peters and associates ${ }^{18}$ found a significant association between sepsis and a reduced TLCO at six months compared with a group that did not develop sepsis. Although anecdotal reports have also suggested an association between necrotising Gram negative pneumonia and subsequent physiological impairment, ${ }^{53}$ Peters et al found no relation between nosocomial pneumonia and chronic pulmonary function.

The severity of ARDS is probably the only variable having prognostic importance for subsequent pulmonary dysfunction. Ghio et al, ${ }^{21}$ and Elliott $e t a l,{ }^{48}$ in studies of 41 and 16 survivors of ARDS respectively, reported that subsequent pulmonary function correlated with the degree of abnormality in thoracic compliance, pulmonary artery pressure, and shunt fraction measured during the first days of illness. Patients with chronic abnormalities of pulmonary function required longer mechanical ventilation and higher levels of PEEP. Peters et $a l^{18}$ found that patients with increased pulmonary vascular resistance, pulmonary arterial pressures, and $\mathrm{A}-\mathrm{aDo}_{2}$ measured on days 4-7 of their acute episode of ARDS had lower values of FVC, FEV 1 , and TLCO. The presence of barotrauma and the need for an $\mathrm{FIO}_{2}>0.6$ for longer than 24 hours has been associated with a reduced TLCo measured one year later. ${ }^{23}$ Two other small studies found no correlation between abnormalities of lung function and (1) the severity of ARDS, (2) the duration of mechanical ventilation, ${ }^{15}$ (3) the duration of PEEP therapy, or (4) the initial arterial oxygen tension. ${ }^{31}$ Despite these contradictions most of the data support the association between the severity of ARDS and chronic pulmonary dysfunction.

\section{Effect of management of ARDS on subsequent pulmonary function}

Care of patients with ARDS is often described as being "supportive" in that no specific treatment for the pathophysiological abnormalities - that is, acute lung inflammation - has been described. It is important to consider the possibility that some aspects of this support, in particular mechanical ventilation and hyperoxia, may actually contribute to the severity of the acute episode and therefore potentially affect the degree of pulmonary dysfunction in the survivors.

LUNG VOLUME AND POSITIVE END EXPIRATORY PRESSURE Numerous studies in animals have shown that positive pressure ventilation at high inspiratory pressures causes acute lung injury. ${ }^{54-60}$ Two important studies showed that it is the large tidal volumes generated by the increased inspiratory pressure, rather than the high pressure itself, that is responsible for the injury. Hernandez et $a l^{61}$ compared the effects of ventilating two groups of rabbits with high peak inspiratory pressures. One group was placed in full body plaster casts and the second group was not. The injury produced by high peak inspiratory pressure in the control group (manifested as increased microvascular permeability) was completely prevented by the plaster cast which limited the end inspiratory volume. Dreyfuss and coworkers $^{62}$ reported similar findings using chest strapping to control inspiratory volume.

The tidal volume required to cause lung injury in animals with otherwise normal lungs is generally higher than that used in clinical practice. Smaller tidal volumes can cause this type of damage in patients with ARDS because the lung inflammation, oedema and atelectasis are not homogeneously distributed. Accordingly, there are significant differences in local alveolar compliance such that areas of normal lung (that have normal compliance) will expand to a greater extent than areas that are injured (with lower compliances). ${ }^{6364}$ Although no well designed trials have investigated whether ventilating with low tidal volumes can reduce mortality or acute or long term morbidity in humans, a recent retrospective uncontrolled study suggests that this may be the case. Hickling and colleagues $^{65}$ reported the results of 50 patients with severe ARDS who were ventilated with low tidal volumes. The partial pressure of arterial $\mathrm{CO}_{2}$ was allowed to rise to a mean of $60 \mathrm{~mm} \mathrm{Hg}$. The mortality in these patients was only $16 \%$, considerably better than other published results. ${ }^{56}$ Decreased mortality has also been reported using "permissive hypercapnia" in ventilated patients with status asthmaticus. ${ }^{66}$

If tidal volume is kept constant, PEEP will increase peak and mean airway pressure as well as end inspiratory and end expiratory lung volumes. Accordingly, the level of PEEP can also cause or contribute to lung injury. Because the most severe cases of ARDS generally are treated with higher levels of PEEP to prevent hypoxaemia, it is difficult to distinguish between a deleterious effect of PEEP and the effects of ARDS itself.

Most experimental evidence argues that low levels of PEEP protect the lung from ventilator associated injury. Webb and Tierney first noted in animals that $5 \mathrm{~cm} \mathrm{H}_{2} \mathrm{O}$ of PEEP reduced the amount of oedema caused by ventilation at high inflation pressures (and volumes). ${ }^{60}$ This protective effect has been supported by other investigators using models of both hydrostatic oedema ${ }^{67}$ and increased permeability oedema. ${ }^{6268}$ Although PEEP does not reduce lung water and may actually increase it, ${ }^{69-71}$ it redistributes the oedema away from alveoli into the interstitium, ${ }^{72}$ and also prevents depletion of surfactant that results from lungs being ventilated at low end expiratory volumes. ${ }^{607374}$

The level of PEEP has been shown by some to correlate inversely with long term pulmonary function. ${ }^{21}{ }^{48}$ Elliott and coworkers reported that survivors of ARDS with abnormalities of lung function were more likely to have received higher levels of PEEP than those with normal function..$^{23}$ In contrast, Peters et al ${ }^{18}$ reported that higher levels of PEEP during the first week of ventilator support were associated with more normal values of TLC and FVC measured more than six months after the acute episode. Patient characteristics, predisposing conditions, and severity of disease do not seem to explain these differences.

$\mathrm{FIO}_{2}$

The level to which $\mathrm{FIO}_{2}$ must be raised to correct hypoxaemia is another marker for the severity of the acute episode. The effect of oxygen on the course of patients with ARDS is difficult to ascertain because those with the worst disease require the most intensive support. In addition, there is no histological difference between ARDS and oxygen toxicity. ${ }^{75}$ Ample animal data suggest that hyperoxia can create or worsen pulmonary injury..$^{75-80}$ In animal models of oleic acid-induced acute lung injury, breathing $40 \%{ }^{81}$ or $50 \%{ }^{82}$ oxygen causes no additional lung injury while $100 \%$ oxygen results in progressive oedema and dysfunction.

There are obviously no studies examining the effects of chronic hyperoxia on normal subjects. Because there are considerable species variabilities with regard to susceptibility to oxygen toxicity, ${ }^{77}$ the relevance of animal studies to patients with ARDS is uncertain. In humans, Van de Water $e t a l^{83}$ found no significant physiological differences between healthy individuals breathing $100 \%$ oxygen for 6-12 hours and those breathing air. Singer et al ${ }^{84}$ reported 
no physiological or clinical difference between patients breathing $100 \%$ oxygen for 24 to 48 hours after cardiac surgery and those breathing $40 \%$ oxygen. Bronchoalveolar lavage specimens from normal volunteers obtained after breathing $95 \%$ oxygen for 17 hours show evidence of capillary leak and effector cell activation, but these changes resolve completely within two weeks of ceasing exposure. ${ }^{85}$ In contrast, in patients with irreversible brain damage, breathing $100 \%$ oxygen caused a time-dependent deterioration of pulmonary function and progressive hypoxaemia was first noted at 40 hours. ${ }^{86}$

There is no agreement as to whether breathing high inspired oxygen concentrations affects long term pulmonary function in survivors of ARDS. Elliott $e t a l^{3}$ found that the only variable correlating with a reduced TLCo was the duration of exposure to an $\mathrm{FIO}_{2}>0.6$. In contrast, Peters et $a l^{18}$ and Yahav et $a l^{15}$ found no correlation between the $\mathrm{FIO}_{2}$ or the duration of oxygen exposure and impairment of pulmonary function.

PEEP is used to try to reduce $\mathrm{FIO}_{2}$ to a "safe" level, generally $<0.7$ or 0.6 . This approach seems reasonable, although it should be recognised that the effect of chronic hyperoxia on humans with acute lung injury has not been defined, the $\mathrm{FIO}_{2}$ that can be considered "safe" is not known, and PEEP itself may be detrimental. In an attempt to provide adequate oxygenation without using high $\mathrm{FIO}_{2}$ values or PEEP, investigators have studied extracorporeal membrane oxygenation and haemofiltration. Unfortunately these modes of support have not been found to alter morbidity or mortality. ${ }^{87}$ The prone position may significantly decrease shunt and increase the $\mathrm{PaO}_{2}$, allowing a reduction in PEEP, or the level of $\mathrm{FIO}_{2}$, or both in at least $50 \%$ of the patients in whom it is used. ${ }^{88-90}$

\section{Summary and conclusions}

Most survivors of ARDS have persistent mild reductions of TLCo even as long as a year after their episode. The lung volumes and flows return to normal in most instances, although a subset of patients will have persistent impairment. Both obstructive and restrictive deficits may be seen. This group may be predicted by the degree of acute lung injury assessed by the level of $\mathrm{FIO}_{2}, \mathrm{PEEP}$, and gas exchange abnormality that exists in the first few days.

In the first year after ARDS most physiological abnormalities will improve, but if deficits persist at one year further improvement is unlikely. Although many patients report dyspnoea following ARDS, the symptom does not correlate with abnormalities of pulmonary function.

The possibility that conventional management may augment the degree of acute injury and worsen outcome must be considered. The effects of chronic hyperoxia in humans with acute lung injury or those of high levels of PEEP compared with low levels are not known. Exploring new ventilator management strategies ${ }^{91}$ while we await more specific treatment directed at the primary problem of acute lung inflammation will hopefully reduce acute mortality as well as acute and chronic morbidity.

Pulmonary and Critical Care Medicine, University of Washington Medical Center,

R HERT Seattle, Washington 98195 , USA

R K ALBERT

Reprint requests to Dr $\mathrm{R}$ K Albert.

1 Pepe P, Potkin R, Reus D, Hudson L, Carrico C. Clinical predictors of the adult respiratory distress syndrome. Am f Surg 1982;144:124-30.

2 Maunder R. Clinical prediction of the adult respiratory distress syndrome. Clin Chest Med 1985;6:413-26.

3 Fowler A, Hamman R, Good J. Adult respiratory distress syndrome: risk with common predispositions. Ann Intern Med 1983;98:593-7.

4 Petty T. ARDS: refinement of concept and redefinition. Am Rev Respir Dis 1988;138:724.
5 Fowler A, Hamman R, Zerbe G, Benson K, Hyers T. Adult respiratory distress syndrome. Prognosis after onset. Am Rev Respir Dis 1985 132:472-8.

6 Sloane P, Gee M, Gottlieb J, Albertine K, Peters S, Burns J, et al. A multicenter registry of patients with acute respiratory distress syndrome. Am Rev Respir Dis 1992;146:419-26.

7 Montgomery A, Stager M, Carrico C, Hudson L. Causes of mortality with the adult respiratory distress syndrome. Am Rev Respir Dis 1985;132:4859.

8 Ashbaugh D, Petty T, Bigelow D, Harris T. Continuous positive-pressure breathing (CPPB) in adult respiratory distress syndrome. $\mathcal{f}$ Thorac Cardiovasc Surg 1969;57:31-9.

9 Douglas M, Downs J. Pulmonary function following severe acute respiratory failure and high levels of positive end-expiratory pressure. Chest 1977;71:18-23.

10 Elliott G, Morris A, Cengiz M. Pulmonary function and exercise gas exchange in survivors of adult respiratory distress syndrome. Am Rev Respir Dis 1981;123:492-5.

11 Khan F, Parekh A. Reversible platypnea and orthodeoxia following recovery from adult respiratory distress syndrome. Chest 1979;75:526-8.

12 Leechawengwong $M$, Berger $H$, Jayamanne $D$. Long-term serial follow-up after two episodes of heroin-induced adult respiratory distress syndrome. Mt Sinai $\mathcal{f}$ Med 1979;46:119-21.

13 Llamas R. Adult respiratory distress syndrome. Report of survival after two episodes. Chest 1974;65:468-9.

14 Rotman H, Lavelle T, Dimcheff D, VandenBelt R, Weg J. Long-term physiologic consequences of the adult respiratory distress syndrome. Chest 1977;71:190-2.

15 Yahav J, Lieberman P, Mollo M. Pulmonary function following the adult respiratory distress syndrome. Chest 1978;74:247-50.

16 Yernault J, Englert M, Sergysels R, DeCoster A. Pulmonary mechanics and diffusion after "shock lung". Thorax 1975;30:252-7.

17 Alberts W, Priest G, Moser K. The outlook for survivors of ARDS. Chest 1983;84:272-4.

18 Peters J, Bell R, Prihoda T, Harris G, Andrews C, Johanson W. Clinical determinants of abnormalities in pulmonary functions in survivors of the adult respiratory distress syndrome. Am Rev Respir Dis 1989;139:1163-8.

19 Halevy A, Sirik Z, Yehuda G, Lewinsohn G. Long-term evaluation of patients following the adult respiratory distress syndrome. Respir Care patients following:132-7.

20 Lakshminarayan S, Stanford R, Petty T. Prognosis after recovery from adult respiratory distress syndrome. Am Rev Respir Dis 1976;113:7-16.

21 Ghio A, Elliot C, Crapo R, Berlin S, Jensen R. Impairment after adult respiratory distress syndrome. An evaluation based on American Thoracic Society recommendations. Am Rev Respir Dis 1989;139:1158-62.

22 Elliott C, Rasmussen B, Crapo R. Upper airway obstruction following adult respiratory distress syndrome. Chest 1988;94:526-30.

23 Elliott G, Rasmusson B, Crapo R, Morris A, Jensen R. Prediction of pulmonary function abnormalities after adult respiratory distress syndrome (ARDS). Am Rev Respir Dis 1987;135:634-8.

24 Eissa N, Ranieri V, Corbeil C, Chasse M, Broidy J, Milic-Emili J. Effects of positive end-expiratory pressure, lung volume, and inspiratory flow on interrupter resistance in patients with ARDS. Am Rev Respir Dis 1991;144:538-43.

25 Pesenti A, Pilosi P, Rossi N, Virtuani A, Brazzi L, Rossi A. The effect of positive end-expiratory pressure on respiratory resistance in patients with the adult respiratory distress syndrome and in normal anesthetized subjects. Am Rev Respir Dis 1991;144:101-7.

26 Tantucci C, Corbeil C, Chasse M, Robatto F, Nava S, Braidy J, et al. Flow and volume dependence of respiratory system flow resistance in patient with adult respiratory distress syndrome. Am Rev Respir Dis 1992;145:355-60.

27 Wright $P$, Bernard $G$. The role of airflow resistance in patients with the adult respiratory distress syndrome. Am Rev Respir Dis 1989;139:116974.

28 Simpson D, Goodman M, Spector S, Petty T. Long-term follow-up and bronchial reactivity testing in survivors of the adult respiratory distress syndrome. Am Rev Respir Dis 1978;117:449-54.

29 Fallat R, Tucker H, Segovia L. Lung function in long-term survivors from severe respiratory distress syndrome (abstract). Am Rev Respir Dis severe respiratory distr.
$1976 ; 113$ (Suppl 1):181.

30 Buchser E, Leuenberger P, Chiolero R, Perret C, Freeman J. Reduced pulmonary capillary blood volume as a long-term sequel of ARDS. Chest 1985;87:608-11.

31 Klein J, van Haeringen J, Sluiter H, Holloway R, Peset R. Pulmonary function after recovery from the adult respiratory distress syndrome. Chest 1976;69:350-5.

32 Churg A, Golden J, Fligiel S, Hogg J. Case reports. Bronchopulmonary dysplasia in the adult. Am Rev Respir Dis 1983;127:117-20.

33 Slavin G, Nunn J, Crow J, Dore C. Bronchiolectasis: a complication of artificial ventilation. $B M \mathcal{F}$ 1982;285:931-4.

34 Northway W, Moss R, Carlisle K, Parker B, Popp R, Pitlick P, et al. Late pulmonary sequelae of bronchopulmonary dysplasia. $N$ Engl $\boldsymbol{f} \mathrm{Med}$ pulmonary seque

35 Philip A. Oxygen plus pressure plus time: the etiology of bronchopulmonary dysplasia. Pediatrics 1975;55:44-50.

36 Wohl M. Bronchopulmonary dysplasia in adulthood. $N$ Engl f Med 1990;323:1834-5.

37 Bader D, Ramos A, Lew C, Platzker A, Stabile M, Keens T. Childhood sequelae of infant lung disease: exercise and pulmonary function abnormalities after bronchopulmonary dysplasia. $\mathcal{f}$ Pediatr $1987 ; 110: 448-56$.

38 Bachofen $M$, Weibel $E$. Alterations of the gas exchange apparatus in adult respiratory insufficiency associated with septicemia. Am Rev Respir Dis 1977;116:589-616.

39 Greene R, Zapol W, Snider M, Reid L, Snow R, Novelline R. Early bedside detection of pulmonary vascular occlusion during acute respiratory failure. Am Rev Respir Dis 1981;124:593-601.

40 Tomashefski J, Davies P, Boggis C, Greene R, Zapol W. The pulmonary vascular lesions of the adult respiratory distress syndrome. Am $\mathcal{f}$ Patho 1983;112:112-26.

41 Snow R, Davies P, Pontoppidan H, Zapol W, Reid L. Pulmonary vascular remodelling in adult respiratory distress syndrome. Am Rev Respir Dis 1982;126:887-92.

42 Saldeen $T$. Trends in microvascular research. The microembolism syndrome. Microvasc Res 1976;11:227-9. 
43 Winterbauer $R$, Ludwig $\mathbb{W}$, Hammar $S$. Clinical course, management and long term sequelae of respiratory failure due to influenza viral pneumonia. fohns Hopkins Med $\mathcal{1} 1977 ; 141: 148-55$.

44 Pearson $R$, Hall W, Menegris M, Douglas R. Diffuse pneumonitis due to adenovirus type 21 in a civilian. Chest 1980;78:107-9.

45 Fowler A, Giclas P, Hyers T. Protein and cell content of bronchoalveolar lavage fluid from patients with adult respiratory distress syndrome. $A m$ Rev Respir Dis 1981;123:S247.

46 Reynolds $\mathrm{H}$, Chretien J. Respiratory tract fluids: analysis of content and contemporary use in understanding lung disease. Dis Mon 1984;30:1-103.

47 Martin T, Raghu G, Maunder R, Springmeyer S. The effects of chronic bronchitis and chronic air flow obstruction on lung cell population recovered by bronchoalveolar lavage. Am Rev Respir Dis 1985;132:254 60.

48 Elliott C, Crapo R, Rasmussen B. Does prior cigarette smoking affect the recovery of pulmonary function after ARDS (abstract)? Am Rev Respir recovery of pulmonary
Dis 1987;135:A428.

49 Ashbaugh D, Petty T. Sepsis complicating the adult respiratory distress syndrome. Surg Gynecol Obstet 1972;135:865-9.

50 Bell R, Coalson J, Smith J, Johanson W. Multiple organ system failure and infection in adult respiratory distress syndrome. Ann Intern Med 1983;99:293-8.

51 Crouch T, Higuchi J, Coalson J, Johanson W. Pathogenesis and prevention of nosocomial pneumonia in a nonhuman primate model. Am Rev Respir Dis 1984;130:502-4

52 Campbell $G$, Coalson J, Johanson $W$. The effect of bacterial superinfection on lung function after diffuse alveolar damage. Am Rev Respir Dis on lung function

53 Hudson L. Prognosis: immediate and long-term sequelae of acute respiratory failure. Respir Care 1983;28:663-71.

54 Hernandez L, Coker P, May S, Thompson A, Parker J. Mechanical ventilation increases microvascular permeability in oleic acid-injured lungs. f Appl Physiol 1990;69:2057-61.

55 Parker J, Hernandez L, Longenecker G, Peevy K, Johnson W. Lung edema caused by high risk peak inspiratory pressures in dogs. Am Rev Respir Di 1990;142:321-8.

56 Parker J, Townsley M, Rippe B, Taylor A. Increased microvascular permeability in dog lungs due to high peak airway pressures. $\mathcal{f} A p p$ Physiol 1984;57:1809-16.

57 Dreyfuss D, Basset G, Soler P, Saumon G. Intermittent positive-pressure hyperventilation with high inflation pressures produces pulmonary hyperventilation with high inflation pressures produces pulmoscular injury in rats. Am Rev Respir Dis 1985;132:880-4.

58 Kolobow T, Moretti M, Fumagalli R, Mascheroni D, Prato P, Chen V, et al. Severe impairment in lung function induced by high peak airway pressure during mechanical ventilation. Am Rev Respir Dis 1987;135: pressure

59 Tsuno K, Prato $P$, Kolobow T. Acute lung injury from mechanical ventilation at moderately high airway pressures. $f$ Appl Physio 1990;69:956-61.

$60 \mathrm{Webb} \mathrm{H}$, Tierney D. Experimental pulmonary edema due to intermittent positive pressure ventilation with high inflation pressures. Protection by positive end-expiratory pressure. Am Rev Respir Dis 1974;110:556-65.

61 Hernandez L, Peevy K, Moise A, Parker J. Chest wall restriction limits high airway pressure-induced lung injury in young rabbits. 7 Appl Physiol 1989;66:2364-8.

62 Dreyfuss D, Soler P, Basset G, Saumon G. High inflation pressure pulmonary edema. Respective effects of high airway pressure, high tidal vulmonary edema. Respective effects of high airway pressure, high tidal volume, and posi

63 Gattinoni L, Pesenti A, Bombino M, Baglioni S, Rivolta M, Rossi F, et al. Relationships between lung computed tomographic density, gas exchange, and PEEP in acute respiratory failure. Anesthesiology 1988;69:824-32.

64 Gattinoni L, Pelosi P, Pesenti A, Brazzi L, Viotale G, Moretto A, et al. CT scan in ARDS: clinical and physiopathological insights. Acta Anaesthesiol Scand 1991;35:87-96.

65 Hickling $\mathrm{K}$, Henderson S, Jackson R. Low mortality associated with low volume pressure limited ventilation with permissive hypercapnia in severe adult respiratory distress syndrome. Int Care Med 1990;16:372-7.

66 Darioli R, Perret C. Mechanical controlled hypoventilation in status asthmaticus. Am Rev Respir Dis 1984;129:385-7.
67 Bshouty Z, Ali J, Younes M. Effect of tidal volume and PEEP on rate of edema formation in in situ perfused canine lobes. $f$ Appl Physiol 1988;64:1900-7.

68 Corbridge T, Wood L, Crawford G, Chudoba M, Yanos J, Sznajder J Adverse effects of large tidal volume and low PEEP on canine acid aspiration. Am Rev Respir Dis 1990;142:311-5.

69 Pang L, Rodriguez-Martinez F, Stalcup S, Mellins R. Effect of hyperinflation and atelectasis on fluid accumulation in the puppy lung. 7 Appl Physiol 1978;45:284-8.

70 Demling R, Staub N, Edmonds $\mathrm{H}$. Effect of end-expiratory airway pressure on accumulation of extravascular lung water. 7 Appl Physiol 1975;38:90712

71 Albert R, Lakshminarayan S, Kirk W, Butler J. Lung inflation can cause pulmonary edema in zone I of in-situ dog lungs. $f$ Appl Physiol:Respir Environ Exercise Physiol 1980;49:815-9.

72 Pare P, Warriner B, Baile E, Hogg J. Redistribution of pulmonary extravascular water with positive end-expiratory pressure in canine pulmonary edema. Am Rev Respir Dis 1983;127:590-3.

73 McClenahan J, Urtnowski A. Effect of ventilation on surfactant, and its turnover rate. F Appl Physiol 1967;23:215-20.

74 Wyszogrodski I, Kyei-Aboagye K, Taeusch H, Avery M. Surfactant inactivation by hyperventilation: conservation by end-expiratory pressure. $\mathcal{f}$ Appl Physiol 1975;38:461-6.

75 Deneke S, Fanburg B. Normobaric oxygen toxicity of the lung. $N$ Engl $\mathcal{F}$ Med 1980;303:76-86.

76 Hayatdavoudi G, O'Neil J, Barry B, Freeman B, Crapo J. Pulmonary injury in rats following continuous exposure to $60 \% \mathrm{O}_{2}$ for seven days. $\mathcal{F} \mathrm{Appl}$ Physiol 1981;51:1220-31.

77 Frank L, Bucher J, Roberts R. Oxygen toxicity in neonatal and adult animals of various species. $\mathcal{f}$ Appl Physiol 1978;45:699-704.

78 De Los Santos R, Seidenfeld J, Anzuetto A, Collins J, Coalson J, Johanson $\mathrm{W}$, et al. One hundred percent oxygen lung injury in adult baboons. $\mathrm{Am}$ Rev Respir Dis 1987;136:657-61.

79 Riley D, Kramer M, Kerr J, Chae C, Yu J, Berg R. Damage and repair of lung connective tissue in rats exposed to toxic levels of oxygen. Am Rev Respir Dis 1987;135:441-7.

80 Witschi H, Haschek W, Klein-Szanto A, Hakkinen P. Potentiation of diffuse lung damage by oxygen: determining variables. Am Rev Respir Dis 1981;123:98-103.

81 De Los Santos R, Coalson J, Holcomb J, Johanson W. Hyperoxia exposure in mechanically ventilated primates with and without previous lung injury. Exp Lung Res 1985;9:255-75.

82 Cheney F, Huang T, Gronka $R$. The effects of $50 \%$ oxygen on the resolution of pulmonary injury. Am Rev Respir Dis 1980;122:373-9.

83 Van De Water J, Kagey K, Miller I, Parker D, O'Connor N, Sheh J, et al. Response of the lung to six to 12 hours of 100 per cent oxygen inhalation in normal man. $N$ Engl $\mathcal{F}$ Med 1970;283:621-6.

84 Singer M, Wright F, Stanley L, Roe B, Hamilton W. Oxygen toxicity in man. A prospective study in patients after open-heart surgery. $N$ Engl f Med 1970;283:1473-8.

85 Davis B, Rennard S, Bitterman P, Crystal R. Pulmonary oxygen toxicity. Early reversible changes in human alveolar structures induced by hyperoxia. N Engl f Med 1983;309:878-83.

86 Barber $R$, Lee J, Hamilton $W$. Oxygen toxicity in man. A prospective study in patients with irreversible brain damage. $N$ Engl $\mathcal{F}$ Med 1970;283:147884.

87 Zapol W, Snider M, Hill J. Extracorporeal membrane oxygenation in severe acute respiratory failure. $\mathcal{f} A M A 1979 ; 242: 2193-6$.

88 Albert $R$, Leasa D, Sanderson $M$, Robertson $H$. The prone position improves arterial oxygenation and reduces shunt in oleic acid-induced acute lung injury. Am Rev Respir Dis 1987;135:628-33.

89 Douglas W, Rehder K, Beynen F, Sessler A, Marsh H. Improved oxygenation in patients with acute respiratory failure: the prone position. Am Rev Respir Dis 1977;115:559-66.

90 Langer M, Mascheroni D, Marcolin R, Gattinoni L. The prone position in ARDS patients. A clinical study. Chest 1988;94:103-7.

91 Marini J, Kelsen S. Editorial: Re-targeting ventilatory objectives in adult respiratory distress syndrome. New treatment prospects: persistent questions. Am Rev Respir Dis 1992;146:2-3. 